\title{
Rede de apoio social e afetivo e estratégias de enfrentamento na doença falciforme: um olhar sobre a pessoa e a família
}

Social and affective network support and coping strategies in sickle cell disease: a look at the person and family

Red de apoyo social y afectivo y estrategias de enfrentamiento de la enfermedad de células falciformes: una mirada sobre la persona y la familia

\author{
Tatiane Lebre Dias* \\ Luciane Laura Godoy Leite*
}

\begin{abstract}
Resumo
Este estudo objetivou caracterizar a rede de apoio social e afetiva e conhecer as estratégias de enfrentamento utilizadas por familiares de pessoas com doença falciforme (DF). A amostra foi composta por 20 sujeitos, sendo sete adultos portadores da doença, que frequentam a Associação dos Falciformes de Mato Grosso (Asfamt), e seus familiares ( $n=13)$. O estudo foi desenvolvido com base em uma abordagem descritiva e exploratória, com emprego do seguinte instrumental: a) entrevista semiestruturada para o portador de DF; b) entrevista semiestruturada para o familiar; c) questionário sociodemográfico; d) escala modo de enfrentamento de problema (EMEP); e e) mapa dos cinco campos. Os resultados apontaram uma média de 28 contatos na rede de apoio dessa amostra, sendo a maioria considerada contato satisfatório. $\mathrm{O}$ enfrentamento focalizado no problema foi o mais utilizado pelos familiares. $\mathrm{O}$ conhecimento de rede de apoio e estratégias de enfrentamento de familiares de portadores de DF permite o planejamento de intervençôes psicossociais mais eficazes e promotoras de qualidade de vida para essa população.
\end{abstract}

Palavras-chave: Rede de apoio. Enfrentamento. Doença falciforme. Família.

\section{Abstract}

This study characterized the social and emotional network of support and investigated the coping strategies used by family members of people

Texto recebido em janeiro 2013 e aprovado para publicação em novembro de 2013.

Doutora em Psicologia, professora adjunta do Departamento de Psicologia da Universidade Federal de Mato Grosso

(UFMT).E-mail: tatianelebre@gmail.com.

2** Psicóloga graduada na UFMT. E-mail: luciane.godoy@gmail.com. 
with sickle cell disease. The sample consisted of 20 subjects, 7 patients with the disease and 13 relatives, who were part of Mato Grosso Sickle Cell Disease Association. To conduct the survey were used a descriptive and exploratory approach, using the following instruments: a) semistructured interview for the carrier; b) semi-structured interview for the family; c) socio-demographic questionnaire; d) The ways of Coping Scale; and e) Map of the Five Fields. The results showed an average of 28 contacts in social support in this sample, the majority considered this satisfactory contact. The problem, focused coping was used more often by family members. The knowledge about network of support and coping strategies of this group, allows psychosocial interventions planning more effective and promote quality of life for this population.

Keywords: Network support. Coping. Sickle cell disease. Family.

\section{Resumen}

Este estudio tuvo como objetivo caracterizar la red de apoyo social y afectivo y conocer estrategias de enfrentamiento utilizadas por familiares de personas con la enfermedad de células falciformes. La muestra estaba formada por 20 sujetos, siete de ellos adultos con esta enfermedad, que participan en la Asociación de los Falciformes de Mato Grosso (Asfamt) y sus familiares $(n=13)$. El estudio se desarrolló a partir de un enfoque descriptivo y exploratorio, utilizando los siguientes instrumentos: a) entrevistas semiestructuradas para el portador; b) entrevista semiestructurada para el familiar; c) cuestionario sociodemográfico; d) Escala Modo de Enfrentamiento de Problemas (EMEP); y e) mapa de los cinco campos. Los resultados mostraron un promedio de 28 contactos en la red de apoyo de esa muestra, la mayoría considera el contacto satisfactorio. El enfrentamiento focalizado en el problema fue utilizado con más frecuencia por los familiares. El conocimiento de la red de apoyo y estrategias de enfrentamiento por los familiares de portadores de esta enfermedad permite planificar intervenciones psicosociales más eficaces para promover la calidad de vida de esta población.

Palabras clave: Red de apoyo. Enfrentamiento. Enfermedad de células falciformes. Familia.

\section{Introdução}

e acordo com o Ministério da Saúde (Brasil, 2007), a doença falciforme (DF) é uma enfermidade hereditária comum no Brasil. A DF parte do grupo das hemoglobinopatias e se caracteriza por apresentar mutações 
na proteína que constitui as hemácias, o que leva à alteração na distribuição de oxigênio pelo corpo. Tal mutação acaba por falcizar a hemácia (alterando a forma original para o formato de uma "foice"). Essa alteração promove a diminuição da vida média dos glóbulos vermelhos e o fenômeno chamado de vaso-oclusão, isto é, a obstrução dos vasos as sanguíneos, com episódios de dor e lesão de órgãos (Brasil, 2012). Devido a essas complicações, estima-se que $20 \%$ dessa população não atinjam os 5 anos de idade. A expectativa de vida é de 42 anos para os homens e 48 anos para as mulheres (Loureiro \& Rozenfeld, 2005).

No Brasil, a doença é frequente em negros e pardos, também ocorrendo em brancos. Na Região Sudeste do País, a prevalência média de portadores é de $2 \%$, valor que sobe a cerca de $6 \%$ a $10 \%$ entre negros. Estima-se o nascimento de 700 a 1.000 novos casos anuais de doenças falciformes no Brasil. Portanto as doenças falciformes são um problema de saúde pública (Zago, 2001). De acordo com o Ministério da Saúde (Brasil, 2013), no País, a letalidade da DF encontra-se em $80 \%$ de crianças com menos de 5 anos de idade, e a vida média do portador da doença alcança a faixa etária de 48 anos.

Como afirma Zago (2001), a doença originou-se na África, estendeu-se para a Península Arábica, sul da Itália e Índia, chegando às Américas pela imigração forçada de cerca de 4 milhões de africanos levados ao Brasil. Além disso, em terras brasileiras, o alto grau de miscigenação fez com que a incidência da doença fosse alta e estivesse presente mesmo em regióes onde a população afrodescendente não é numericamente representativa.

Apesar de vários estudos indicarem a grande incidência na população, a DF só ganhou destaque após a inclusão do teste de hemoglobinopatias no exame do pezinho, em 2001, e da Política Nacional de Atenção Integral às Pessoas com Doença Falciforme e outras Hemoglobinopatias ("Portaria n. 1.391/ GM") (Silva, Ramalho \& Cassorla, 1993). Entretanto, em um estudo com mulheres negras portadoras de DF, Cordeiro (2009) identificou nos discursos dessas mulheres tratamento descortês, humilhante e injusto, indicando uma discriminação racial e de gênero praticada nos serviços de saúde.

Zago (2001) aponta algumas das manifestações clínicas da doença que explicam as altas morbidade e mortalidade dos portadores falcêmicos: manifestações de anemia crônica, episódios de dores osteoarticulares, dores abdominais, infecções e enfartes pulmonares, retardo do crescimento e maturação sexual, acidente vascular cerebral e comprometimento crônico de múltiplos órgãos, sistemas ou aparelhos, como o sistema circulatório, os rins, olhos e a pele, na forma de úlceras maleolares crônicas. 
Esse quadro clínico, político e social a respeito da DF demanda cuidados e manejos que podem alterar a rotina familiar e promover dificuldades no desenvolvimento da pessoa portadora da doença. Nesse sentido, caracterizar a rede de apoio e conhecer as estratégias de enfrentamento com vistas à promoção da saúde possibilita um olhar para além dos aspectos biológicos limitantes da qualidade de vida dos portadores de DF. O fortalecimento da rede de apoio pode ser um fator de proteção que propicia interações benéficas, estratégias de enfrentamento mais eficazes na resolução dos problemas referentes à doença.

O enfoque nos aspectos saudáveis do desenvolvimento humano, mesmo em situações adversas, está presente na produção do psicólogo Urie Bronfenbrenner (1917-2005), o qual segundo Narvaz e Koller (2004, p. 51), estruturou a "abordagem ecológica do desenvolvimento humano" (AEDH). De acordo com a $\mathrm{AEDH}$, existem quatro núcleos pelos quais é possível estudar a interação da pessoa com o seu contexto. São eles: o processo, a pessoa, o contexto e o tempo (Morais \& Koller, 2004). A dimensão pessoa refere-se às características individuais, genéticas, físicas e psicológicas do indivíduo em desenvolvimento, aspectos cruciais para a sua relação com o mundo social. Já a dimensão contexto inclui tanto os contextos de interação face a face do indivíduo quanto aqueles mais amplos, como sociedade, valores e cultura. Essa dimensão é compreendida com base na interação dos quatro níveis ambientais: microssistema (família e os contatos diretos face a face), mesossistema (escola/trabalho, encontro de vários microssistemas), exossistema (associações, instituições, serviços de saúde) e macrossistema (cultura brasileira, política interna e externa.), e constitui seu ambiente ecológico (Bronfenbrenner, 1996).

Nessa perspectiva, privilegiam-se os aspectos saudáveis do desenvolvimento, analisando a pessoa no maior número possível de ambientes e em contato com diferentes situações e sujeitos. Desse modo, dentro de quadros de estado crônico, como na doença falciforme, é possível lançar o olhar não apenas para os fatores de risco provenientes da enfermidade, mas estudar os fatores de proteção, como a rede de apoio social e afetivo, que auxiliam na superação das adversidades por meio de comportamentos mais apropriados e efetivos (Brito \& Koller, 1999).

De acordo com Sluzki (1997), "rede social pessoal" ou "rede social significativa" vincula-se à visão sistêmica adotada na terapia familiar. Nesse sentido, baseando-se em Gregory Batenson, o autor considera que "as fronteiras do indivíduo não estão limitadas por sua pele, mas incluem tudo aquilo com que o sujeito interage - família, meio físico, etc.” (Sluzki, 1997, p. 37). Nessa perspectiva, a rede compreende todas as interaçóes do indivíduo, ou seja, 
"família, amigos, relaçôes de trabalho, de estudo de inserção comunitária e de práticas sociais" (Sluzki, 1997, p. 37).

Quanto ao aspecto a que se refere ao traçar a fronteira da rede social, Sluzki (1997) considera ser essa uma medida arbitrária, baseada mais em razões práticas que conceituais. De modo indagativo, é possível, segundo Sluzki (1997), discriminar a microrrede pessoal e a macrorrede. A primeira, considerada rede social significativa, e a segunda, compreendida pela comunidade, sociedade, etc.

O debate em torno das redes de apoio social deriva da teoria do apoio social, que tem origem em autores norte-americanos. O apoio social é definido como sendo qualquer informação, falada ou não, e, ou, auxílio material, oferecidos por grupos e, ou, pessoas que se conhecem, que resultam em efeitos emocionais e, ou, comportamentos positivos (Teixeira \& Leão, 2002). Brito e Koller (1999) definem rede de apoio social como um conjunto de sistemas e de pessoas significativas que compóem os elos de relacionamento recebidos e percebidos do indivíduo em seu nicho ecológico.

O apoio social é considerado uma importante dimensão do desenvolvimento, constituindo uma interface entre o sujeito e o sistema social do qual ele faz parte (Garmezy \& Masten, 1991). De acordo com Bronfenbrenner (1996), o apoio afetivo é igualmente fundamental por ser responsável por imprimir qualidade às relaçóes e contribuir para a manutenção dos vínculos. Portanto o apoio social e afetivo está relacionado à percepção de que a pessoa tem de seu mundo social, como se orienta nele, suas estratégias e competências para estabelecer vínculos, e com os recursos que esse lhe oferece, como proteção e força, diante das situações de risco que se apresentam (Brito \& Koller, 1999).

No contexto de doenças crônicas, além das redes de apoio, também se destacam as estratégias ou modos de enfrentamento para a melhoria nas condições de vida. Segundo Seidl, Troccoli e Zannon (2001), desde que Hans Selye realizou pesquisas relacionadas à chamada síndrome de adaptação geral, os estudos sobre o estresse e seus efeitos no processo saúde-doença vêm sendo desenvolvidos. Nesse caso, considera-se o estresse como reação fisiológica do organismo, diante de demandas externas que prejudicavam a sua homeostase. Apartir da década de 1970, teorias psicológicas sobre o fenômeno estresse incorporaram outras variáveis aos modelos explicativos, como as respostas de enfrentamento (coping) e a avaliação cognitiva (appraisal). Desse modo, a perspectiva teórica que 
concebe estresse e enfrentamento com base na interação entre o organismo e seu ambiente tem tido destaque especial na área da psicologia da saúde (Albuquerque, Martins \& Neves, 2008).

Baseado nesse modelo interativo entre o ambiente e o organismo, o enfrentamento é definido como "mudanças constantes nos esforços cognitivos e comportamentais, utilizado pelos indivíduos com objetivo de lidar com demandas específicas, internas ou externas, que são avaliadas como sobrecarregando ou excedendo seus recursos pessoais" (Lazarus \& Folkman, 1984, p. 141).

$\mathrm{Na}$ década de 1980, numa perspectiva cognitivista, Folkman e Lazarus (1984) propuseram um modelo que divide o coping em duas categorias funcionais: coping focalizado no problema e coping focalizado na emoção. Essa construção baseou-se em análises fatoriais que geraram dois fatores principais utilizados pelos pesquisadores para definir os dois tipos de estratégias de coping. Antoniazzi, Dell'aglio e Bandeira (1998, p. 276), ao citarem Ryan-Wenger, destacam que as estratégias de coping são ações que podem ser aprendidas, usadas e descartadas.

Quanto ao coping focalizado no problema, Seidl et al. o definem como um esforço para atuar na situação que deu origem ao estresse, tentando mudála. A função dessa estratégia é alterar o problema existente na relação entre a pessoa e o ambiente que está causando a tensão. Alguns exemplos de estratégias de coping focalizado no problema são expressos em comportamentos como negociar para resolver um conflito interpessoal ou solicitar ajuda prática de outras pessoas. O coping focalizado na emoção, segundo Lazarus e Folkman (1984), é utilizado para manter o otimismo, para negar o fato e suas implicações. É considerado coping focalizado na emoção comportamentos como distanciamento, autocontrole, busca de suporte social, etc. (Folkman, Lazarus, Dunkel-Schetter, DeLongis \& Gruen, 1986).

De acordo com Seidl et al. (2001), na perspectiva de R. S. Lazarus e S. Folkman, o uso de estratégias de coping focalizado no problema ou na emoção depende de uma avaliação da situação estressora que envolve o sujeito. Existem dois tipos de avaliação de acordo com essa teorização. A avaliação primária é um processo cognitivo pelo qual os indivíduos checam qual o risco envolvido em uma determinada situação de estresse. A segunda avaliação corresponde à análise dos recursos disponíveis para lidar com o problema. Em situações avaliadas como modificáveis, o coping focalizado no problema tende a ser empregado, enquanto o coping focalizado na emoção tende a ser mais utilizado nas situações avaliadas como inalteráveis (Antoniazzi et al., 1998, p. 285). 
Mais recentemente, foi apresentada uma terceira estratégia de coping focalizada nas relações interpessoais, na qual o sujeito busca apoio nas pessoas do seu círculo social para a resolução da situação estressante. A ideia desse tipo de resposta iniciou com o trabalho de Coyne e DeLongis (1986) e foi estudada mais aprofundadamente por O'Brien e DeLongis (1996), com o objetivo de entender melhor o papel da personalidade e dos fatores contextuais na escolha das estratégias de coping.

As categorias funcionais de coping focalizado no problema e coping focalizado na emoção foram utilizadas para a construção da "escala modos de enfrentamento de problemas" (EMEP), validada no Brasil por Seidl et al. (2001), e esse modelo de coping como processo de interação indivíduoambiente ou perspectiva cognitiva do coping foi adotado como referencial teórico e metodológico neste trabalho.

As poucas investigações relacionadas à rede de apoio social e afetivo e as estratégias de enfrentamento na doença falciforme impulsionaram este estudo, que investigou as características da rede de apoio social e afetivo e as estratégias de enfrentamento que adotam os familiares de pessoas com doença falciforme.

\section{Metodologia}

O estudo foi desenvolvido de modo descritivo e exploratório, com abordagem qualitativa, que Vieira (2002) destaca como pesquisas que expõem as características de determinada população ou fenômeno, mas não têm o compromisso de explicar os fenômenos que descrevem, embora sirvam de base para tal explicação.

\section{Participantes}

A amostra foi composta inicialmente por 7 portadores de doença falciforme e 13 familiares, totalizando 20 participantes. Os 7 participantes serão denominados pelo grupo familiar (GF1, GF2, GF3, GF4, GF5, GF6 e GF7). Em relação aos grupos familiares, 3 grupos (GF1, GF4 e GF7) foram compostos pelo portador de doença falciforme e 1 familiar; 2 grupos (GF2 e GF3), por um portador e 2 familiares; e 2 grupos (GF6 e GF7) pelo portador e 3 familiares. Como critério de seleção, todos os participantes deveriam ter 18 anos de idade ou mais, fazerem parte da Associação dos Falciformes de Mato Groso (Asfamt) e concordarem em participar do estudo. 
Em relação aos sete portadores da doença, quatro eram do sexo feminino e três do sexo masculino, com idade entre 18 e 52 anos (média=28,29). Todos tinham diagnóstico de doença falciforme segundo os critérios estabelecidos pelo Sistema de Classificação Internacional de Doenças e Problemas Relacionados com a Saúde (CID-10) - D57.0 e estavam listados como membros da Asfamt. A maioria $(n=6)$ dos portadores da doença tem ensino médio completo. Quanto à profissão, observou-se que 4 eram estudantes, 1 era doméstica e 1 era dona de casa. Apenas um deles não trabalhava e não continuou os estudos por complicações decorrentes da doença. Em relação ao estado civil, 6 deles se declararam solteiros e 1, divorciado.

Ao todo, participaram 13 familiares, sendo 9 do sexo feminino e 4 do sexo masculino, com idade entre 30 e 70 anos (média $=47,38$ ). Do total de familiares, $46,1 \%$ consideraram-se negros, $38,4 \%$ declararam-se pardos e apenas $15,3 \%$ denominaram-se como brancos. Quanto à escolaridade, 7,6\% tinham ensino fundamental incompleto; $30,7 \%$, ensino fundamental completo; enquanto $38,4 \%$ tinham ensino médio completo e $23 \%$, ensino superior completo. No que se refere à situação conjugal, 6 declararam-se casados, 2 viviam com companheiros, 2 solteiros, 2 viúvos e 1 divorciado.

Em relação à distribuição da amostra quanto à renda familiar, 7,6\% tinham renda familiar de até um salário mínimo, mais da metade $(53,8 \%)$ tinha renda entre 1 a 3 salários mínimos, $23 \%$ viviam com renda entre 4 e 10 salários mínimos e 15,3\%, com renda entre 10 e 20 salários mínimos. No que se refere à situação empregatícia, 38,4\% eram empregados com direitos trabalhistas, $23 \%$ realizavam atividades autônomas regulares, 7,6\% estavam desempregados e o restante $(30,7 \%)$ estavam divididos entre aposentados e donas de casa.

\section{Material e instrumentos}

Para a realização da pesquisa, foi utilizado o seguinte instrumental:

- entrevista semiestruturada para a pessoa com doença falciforme: em que ela respondeu qual o significado da família para ela e foi requisitada a escolher até três familiares que a ajudassem nos cuidados com a doença;

- entrevista semiestruturada para os familiares: com questões referentes à percepção em relação à doença e as facilidades e dificuldades no tratamento do portador de anemia falciforme;

- questionário sociodemográfico: para caracterização da amostra familiar, desenvolvido especialmente para este estudo. Foram levantados dados 
como sexo, idade, renda, estado civil, situação empregatícia e religião;

- "escala modo de enfrentamento de problemas (EMEP)"(Seidl et al., 2001): para o familiar do portador de doença falciforme. A EMEP, conforme Seidl et al. (2001), foi concebida com base no modelo interativo do estresse e conceitua enfrentamento como um conjunto de respostas específicas para determinada situação estressora. Esse instrumento é composto de 45 itens, distribuídos em 4 fatores:
a) enfrentamento focalizado no problema (18 itens);
b) enfrentamento focalizado na emoção (15 itens);
c) busca de suporte social (5 itens);
d) busca de práticas religiosas (7 itens).

A EMEP usa cinco possibilidades de respostas:
a) eu nunca faço isso;
b) eu faço isso um pouco;
c) eu faço isso às vezes;
d) eu faço isso muito; e
e) eu faço isso sempre. Desse modo, o escore total é obtido pela média aritmética e, quanto mais alto o escore, maior a frequência de utilização da estratégia de enfrentamento;

"mapa dos cinco campos" (Samuelsson, Thernlund \& Ringström, 1996), versão adaptada por Siqueira, Betts \& Dell'aglio, 2006): é um instrumento que avalia estrutura, que corresponde à quantidade de relações estabelecidas na rede, e função, que está relacionada à qualidade dessas relaçôes, com base em cinco campos: família, parentes (família extensa, como padrasto/madrasta), escola/trabalho, amigos e contatos formais. O campo contatos formais representa os lugares que o participante costuma frequentar, como igreja, posto de saúde e outros locais que não estão contemplados nos outros quatro campos. Ao campo escola foi adicionado o trabalho (ficando escola/trabalho), pois os entrevistados eram adultos e, nesse caso, o mundo do trabalho é 
bastante significativo.

O instrumento é constituído por um quadro de feltro e por figuras que representam adultos, adolescentes e crianças, coloridas de acordo com o sexo (azul: masculino; rosa: feminino) e diferenciadas pelo tamanho. Essa forma de aplicação foi desenvolvida para crianças, com o objetivo de torná-lo um instrumento lúdico. Contudo a mostra dessa pesquisa foi composta somente de adultos, o que exigiu uma adaptação. Então o mapa foi aplicado em folhas A4, com cinco círculos concêntricos. O participante escrevia à caneta os nomes das pessoas de sua rede de apoio ou apenas apontava em qual círculo (maior proximidade, menor proximidade ou conflito) as pessoas de seu convívio deveriam ficar, e a pesquisadora anotava no mapa. O círculo central correspondia ao participante, e cada círculo adjacente media a qualidade do vínculo, sendo que quanto mais próximo do círculo central fosse colocada a pessoa, mais satisfação e qualidade havia nesse contato. $O$ último círculo, na periferia do mapa, correspondia às relações insatisfatórias. Esse instrumento também permitia que pessoas já falecidas fossem consideradas parte da rede de apoio, por causa da consideração subjetiva da percepção da rede.

Os dados do mapa dos cinco campos (Siqueira, Betts, Dell'aglio, 2006) foram avaliados de acordo com os seguintes aspectos:

a) estrutura da rede: avaliada pelo número de contatos em toda a rede e por campo;

b) funcionalidade da rede: com base nos seguintes aspectos:

- média dos contatos em cada círculo adjacente ao centro, que representam os níveis de proximidade;

- média dos conflitos e rompimentos;

- fator de proximidade total da rede e por campo. O fator de proximidade é uma variável que representa o grau de vinculação dos participantes com o número de pessoas citadas nos campos, sendo medido pela localização dessas pessoas em relação ao círculo central, no qual está o participante. Para o cálculo desse escore, o número de pessoas colocadas no primeiro nível é multiplicado por oito; no segundo nível, por quatro; no terceiro nível, por dois; no quarto nível, por um; e, no quinto nível, por zero. $\mathrm{O}$ fator de proximidade varia de 0 a 8 , sendo que escores entre 0 e 2,6 são considerados de pequena força; entre 2,7 e 
5,3, média força; e entre 5,4 e 8 , grande força de proximidade. Esse escore permite diferenciar qualidade de quantidade, pois embora um participante mencione 10 contatos em um campo, todos no primeiro nível, terá um maior fator de proximidade nesse campo se comparado a outro participante que mencione os mesmos 10 contatos, entretanto distribuídos nos cinco níveis.

O somatório desse cálculo é dividido pelo número total de pessoas citadas no campo, para a média de proximidade no campo, ou pelo número total de pessoas citadas no mapa, para a média de proximidade no instrumento. Esse fator varia de 0 a 8 , sendo que escores entre 0 e 2,6 são considerados de pequena força; entre 2,7 e 5,3, média força; e entre 5,4 e 8 , grande força de proximidade.

\section{Procedimento}

A pesquisa foi aprovada pelo Comitê de Ética em Pesquisa do Hospital Júlio Müller, de Cuiabá-MT, sob o protocolo de no 043/CEP-HUJM/2011, com concordância da Associação dos Falciformes de Mato Grosso (ASFAMT).

Os instrumentos e entrevistas foram aplicados na residência dos sujeitos da pesquisa, em visitas pré-agendadas. Quanto à indicação dos três familiares pelo próprio portador da doença falciforme, esse recurso foi utilizado para que a amostra de familiares fosse composta apenas por pessoas que têm alguma participação nos cuidados e no enfrentamento desse contexto de saúde-doença. Portanto foram realizadas duas etapas: a primeira com o portador da doença falciforme e a segunda com o familiar indicado por esse portador.

$\mathrm{Na}$ primeira etapa, foi realizada uma sessão única com o portador de doença falciforme: após a apresentação e assinatura do termo de consentimento livre e esclarecido (TCLE), realizou-se a entrevista semiestruturada para conhecer o conceito de família e recolher a indicação de três familiares significativos para ele. O tempo de duração foi de 30 minutos, em média. Logo após, foi aplicado o instrumento mapa dos cinco campos, também com duração de 30 minutos.

$\mathrm{Na}$ segunda etapa, com o familiar do doente falcêmico, houve a apresentação do TCLE, em seguida, foi aplicado o questionário sociodemográfico, depois a escala modo de enfrentamento a problema (EMEP) e, por fim, o mapa dos cinco campos. Após a finalização dos instrumentos, foi aplicada a entrevista 
semiestruturada, para conhecer melhor o envolvimento do familiar com o doente, suas percepçôes sobre as facilidades e dificuldades nos cuidados com o portador de doença falciforme. Todo esse processo teve duração média de 60 minutos.

\section{Resultados}

Em relação à rede de apoio, a estrutura do mapa dos cinco campos indicou um total de 569 contatos, sendo 523 considerados satisfatórios, 45 insatisfatórios, 37 conflitos e 8 rompimentos. A média geral de contatos por pessoa foi de 28,4 ( $\mathrm{DP}=4,24)$, enquanto o total de pessoas presentes na rede, por grupo familiar, ficou entre 41 e 135 pessoas (média=81,2 e DP=7,07). Todos os grupos familiares apresentaram mais contatos satisfatórios que insatisfatórios. Apenas o GF2, GF6 e GF7 não relataram rompimentos. De modo geral, todos os grupos familiares apresentaram pouca quantidade de contatos insatisfatórios e conflitos, sendo que o GF1 foi o grupo com maior número de contatos insatisfatórios $(\mathrm{n}=11)$ e o GF3 e GF5 com maior número de conflito ( $\mathrm{n}=7)$ (gráfico 1).

$$
\text { GF } 6 \quad{ }_{2}{ }_{3}
$$

Gráfí $0_{7} 1$ - Caracterização da rede de apoio por número de contato 132 Sálisiatório, ${ }^{7}$ contato insatisfatório, rompimentos e conflito $105^{1}$ e portadores de

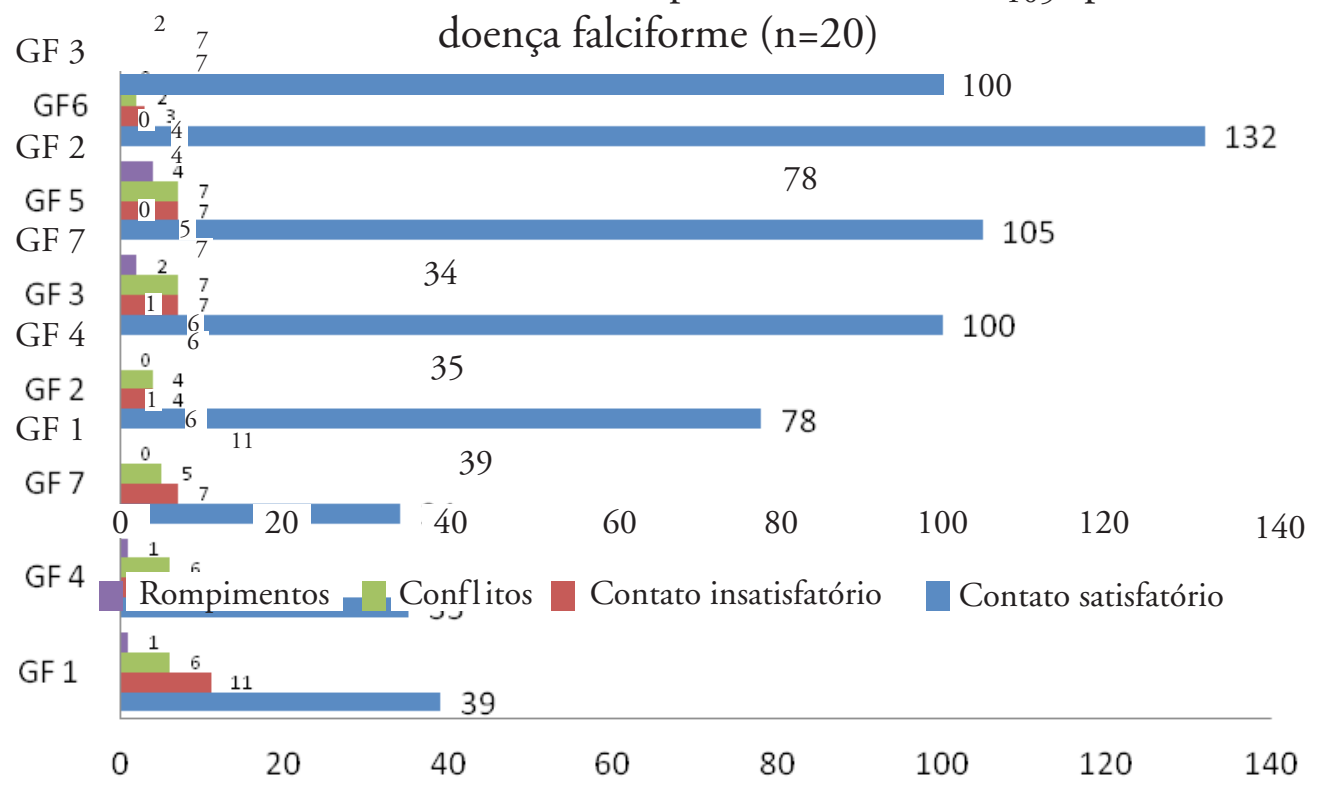

Rompimentos Conflitos Contato Insatisfatório Contato satisfatório

Fonte: Resultados da pesquisa. 
A constituição da rede evidenciou que o campo família apresentou maior frequência entre os grupos familiares, seguido dos campos parentes e amigos e, por último, foram, respectivamente, os campos escola/trabalho e contatos formais. Pela tabela 1, observa-se que o GF3 e GF5, respectivamente, apresentaram maior frequência para os campos parentes e amigos.

Tabela 1 - Frequência por grupo familiar e campo na rede de apoio social $(\mathrm{n}=20)$

\begin{tabular}{lccccc}
\hline & Família & Parentes & Escola/Trabalho & Amigos & Contatos formais \\
\hline GF1 & 14 & 11 & 7 & 13 & 7 \\
GF2 & 23 & 18 & 17 & 13 & 11 \\
GF3 & 23 & 45 & 17 & 10 & 11 \\
GF4 & 15 & 4 & 7 & 10 & 11 \\
GF5 & 28 & 24 & 8 & 31 & 20 \\
GF6 & 42 & 23 & 22 & 26 & 15 \\
GF7 & 13 & 4 & 10 & 10 & 6 \\
TOTAL & 157 & 129 & 88 & 113 & 82 \\
\hline
\end{tabular}

Fonte: Resultados da pesquisa.

No que se refere à função da rede por coeficiente de proximidade, todos os grupos familiares apresentaram valores indicando média força de proximidade. arando os grupos familiares em relação ao número de participantes, ra-se que, no grupo familiar com um portador e um ${ }_{135} \ldots$ iliar, o GF4 ntou menor cototal de pessoas na rede xim Coeficiente de proximidade $\cdot$ ce cocos os grupos, 3 apresentou menor coeficiente de 107 imidade $(112,16)$ (gráfico 2).

82

ico 2 - Total de pessoas na rede de apoio e coeficiente de proximidade, 51 4141 por grupo familiar (GF)

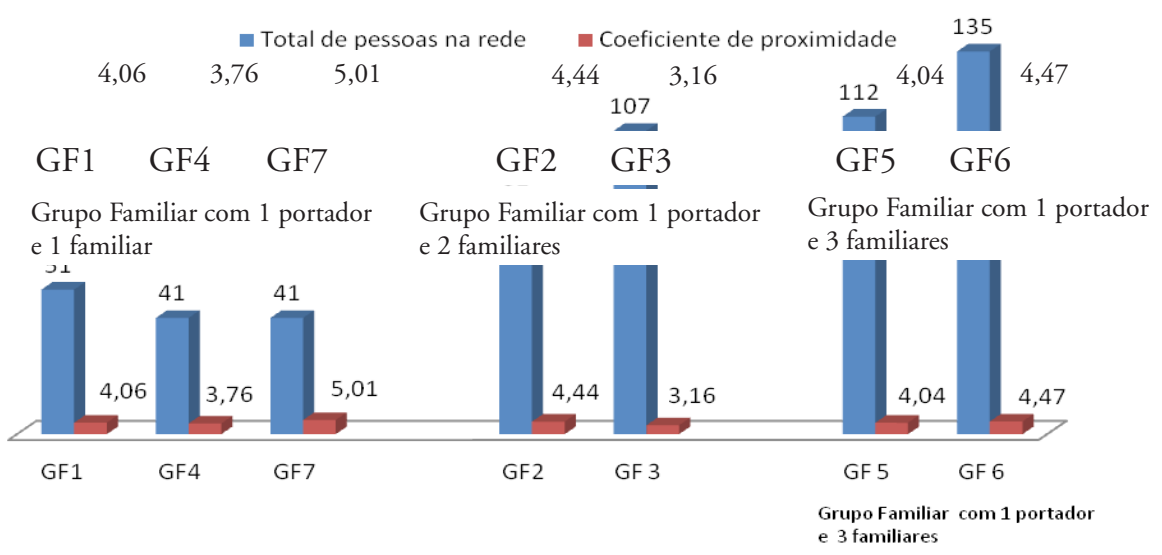

Fonte: Resultados da pesquisa. 
Como citado, o fator de proximidade é uma variável que representa o grau de vinculação dos participantes com o número de pessoas citadas nos campos, sendo medido por meio da localização dessas pessoas em relação ao círculo central, no qual está o participante. Quanto às respostas à entrevista feita aos familiares, foi possível verificar que, dos 13 participantes, 9 desconheciam a doença falciforme até o momento do diagnóstico recebido pelo familiar portador. Apenas 3 participantes afirmaram já conhecer a doença, pois tinham filhos ou outros parentes diagnosticados. Apenas uma pessoa afirmou ter recebido o diagnóstico da doença e ter ficado em "choque" (familiar do portador no 7 , sexo F, 33 anos). Nesse contexto de descoberta da doença, as palavras "surpresa" e "susto" apareceram nas respostas de 7 familiares.

As dificuldades apontadas pelos familiares foram:
a) despreparo dos profissionais da saúde (4 ocorrências);
b) não adesão ao tratamento pelo portador (2 ocorrências);
c) limitações provenientes da doença (2 ocorrências);
d) medo da morte repentina do familiar (2 ocorrências);
e) crise dolorosa (1 ocorrência);
f) problemas financeiros (1 ocorrência). Um familiar afirmou não haver dificuldades.

Já os elementos facilitadores apontados foram:
a) tratamento/remédios (3 ocorrências);
b) amor/carinho (3 ocorrências);
c) informação/instruções médicas (3 ocorrências);
d) condição financeira favorável/plano de saúde (2 ocorrências);
e) ser conhecido nas instituições que podem ajudar (1 ocorrência). Um familiar afirmou não haver facilidades.

Quanto às respostas na EMEP, estas foram classificadas nas seguintes categorias:
a) fator 1 (focalizado no problema);
b) fator 2 (focalizado na emoção); 
c) fator 3 (busca de práticas religiosas); e

GF7 d) fator 4 (busca por suporte social). De acư $3^{2,4}$ lo com os resi 1,1 idos, verificou-se que a 1,6 ioria dos familiares utilizou estratéf, 1 s.s de GF6 enfrentamento focalizado no piư 2,57.a (média=4,05), seguida de busca de práticas religi 1,8 ; (média $=3,46)$ e estratégias de busca por

GF5 suporte social (média $=2,81$ ). A estratégia ${ }_{\mathrm{m}}^{3} 3,13$ os utilizada $\underset{4,07}{f_{n}}$ a de

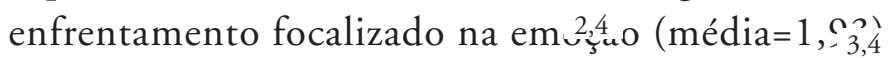

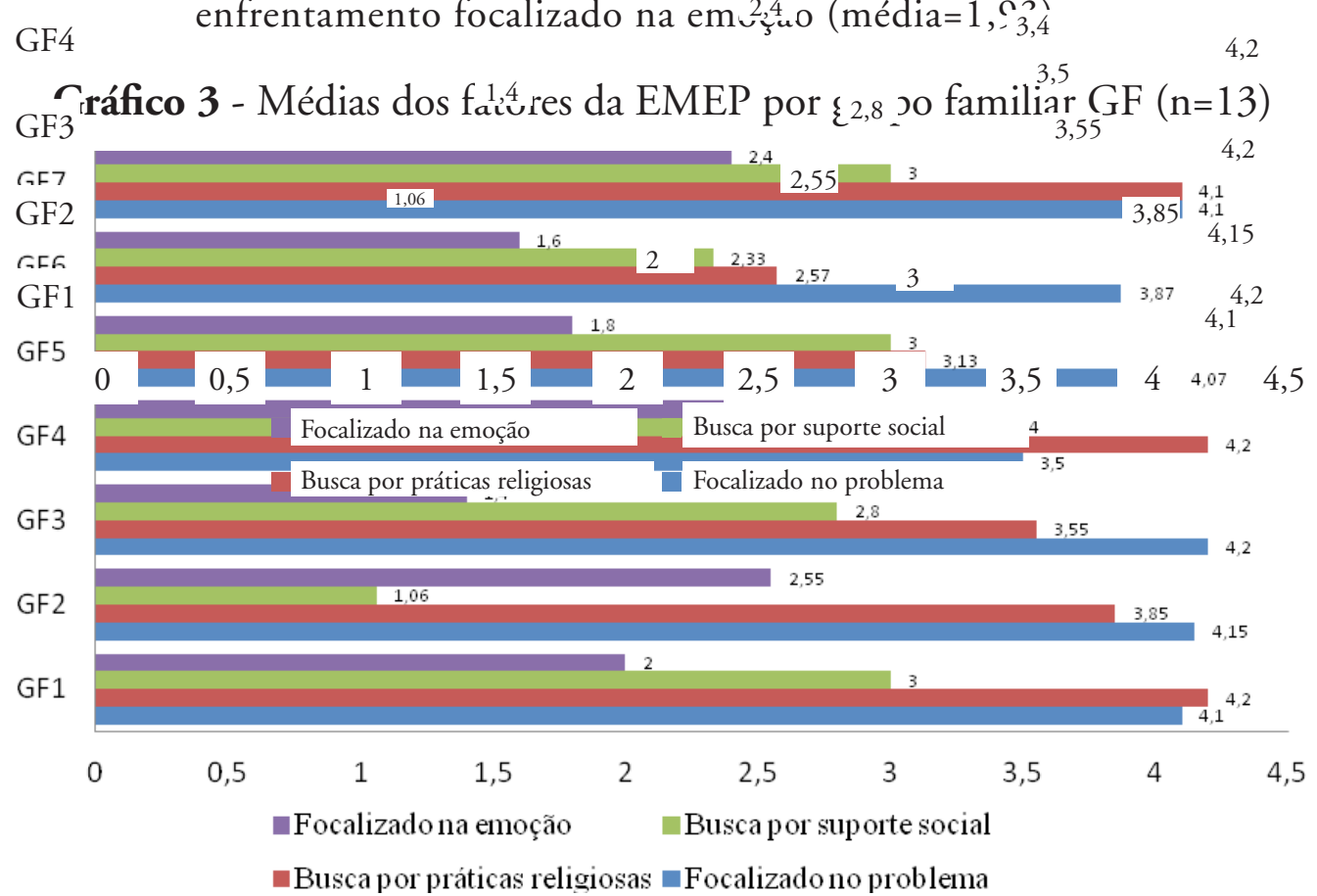

Fonte: Resultados da pesquisa.

Ao se compararem os grupos familiares, nota-se que GF3 foi o grupo que mais utilizou o enfrentamento focalizado no problema (média $=4,2$ ), seguido de GF1, GF2 e GF7 (média= 4,1). O GF6 (média=3,87) e o GF4 (média $=3,5$ ) apresentaram menor média. A busca por práticas religiosas foi a segunda estratégia mais utilizada pelo GF1 e GF4 (média=4,2), e a menos utilizada pelo GF6 (média=2,57) (gráfico 3).

Quanto ao enfrentamento pela busca de suporte social como terceira estratégia mais adotada, na classificação geral, o GF4 apresentou maior média de uso (média $=3,4$ ) e com menor média o GF2 (média=1,06). Por fim, quanto ao enfrentamento focalizado na emoção, estratégia menos utilizada na classificação geral, o GF2 apresentou maior média de uso (média=2,55), enquanto GF3 (média=1,4) foi o grupo que menos utilizou essa estratégia.

\section{Discussão}


No tocante à rede de apoio social e afetivo, Nogueira (2001) considera que descrever a configuração da rede de relações sociais na vida adulta pode contribuir para entender como esse aspecto influencia o processo de adaptação do desenvolvimento adulto ao longo de transições evolutivas. Todos os grupos familiares apresentaram média força de proximidade no mapa dos cinco campos, o que mostra que a rede de apoio social e afetivo, de fato, pode oferecer suporte para o indivíduo portador de doença falciforme. Vale ressaltar que não se trata de ter um grande número de pessoas conhecidas, é necessário que elas possam ser acionadas em um momento de necessidade.

O microssistema familiar foi o que obteve as maiores médias de coeficiente de proximidade e também maior frequência, ou seja, corroborando o fato de "na maioria das vezes, a pessoa numa condição de portadora crônica de alguma patologia necessita compartilhar este enfrentamento com sua família ou com outras pessoas próximas deste grupo social primário" (Silva, Guedes, Moreira \& Souza, 2002).

Em investigação sobre a rede de apoio de cuidadores familiares em uma comunidade remanescente de quilombos, Silveira (2011) verificou que a família foi a mais lembrada por todos os cuidadores. A família também foi apontada como principal fonte de apoio no estudo com adolescentes institucionalizados realizado por Siqueira et al. (2006).

Em relação às estratégias de enfrentamento, mesmo nesse contexto inalterável da doença falciforme, de origem genética e incurável, a estratégia mais utilizada foi o enfrentamento focalizado no problema, diferenciandose do posicionamento de Folkman e Lazarus, conforme relatam Antoniazzi et al. (1998), no qual o coping focalizado na emoção tende a ser utilizado nas situações avaliadas como inalteráveis, enquanto o coping focalizado no problema tende a ser mais empregado em situaçóes avaliadas como modificáveis. Contudo o enfrentamento focalizado na emoção, que busca modificar e regular a maneira como a pessoa se sente e se posiciona diante do problema (neste caso, a doença) foi o menos utilizado.

O estudo de Mensorio, Kohlsdorf e Costa Junior (2009) corrobora os resultados do uso do enfrentamento focalizado no problema entre familiares de pessoas com doenças crônicas (nas fases posteriores ao início do tratamento). Segundo os autores, ao longo do tratamento, os cuidadores tendem a diminuir seus níveis de ansiedade, o que pode significar um processo de abandono do foco na emoção e uma maior atenção para açôes que podem não eliminar a doença, mas amenizam as consequências e os sintomas dela. No grupo pesquisado, no qual os portadores têm 18 anos ou mais, o tratamento tinha 
iniciado há anos, sendo provável que o enfrentamento focalizado no problema fosse útil, por exemplo, nos episódios de crise dolorosa. Além disso, esses comportamentos podem fundamentar-se no cumprimento de instruçôes recebidas da equipe profissional quanto a cuidados com indivíduos doentes (Mensorio et al., 2009).

Neste estudo, que buscou caracterizar a rede de apoio e conhecer as estratégias de enfrentamento de familiares portadores de doença falciforme, embora aborde aspectos conceituais diferenciados, entendese que a rede de apoio do grupo familiar pode se relacionar com a forma como o grupo utiliza estratégias cognitivas de enfrentamento. Nesse sentido, de modo geral, os resultados não permitem estabelecer uma relação entre a maior incidência de contatos satisfatório na rede de apoio e o uso de estratégia focalizada no problema e na busca por práticas religiosas. Por outro lado, verificou-se menor incidência nos grupos familiares investigados de contatos insatisfatórios, rompimentos e conflitos, assim como menor média para uso de estratégias de enfrentamento focalizada na emoção e na busca por suporte social.

A importância da família como rede de apoio pode ser observada no GF4, que obteve o menor coeficiente de proximidade $(3,76)$ e o grupo que mais empregou a estratégia de enfrentamento de busca por suporte social (média $=3,4$ ). O discurso da portadora de doença falciforme desse grupo permite-nos estabelecer a relação entre rede de apoio e estratégia de enfrentamento: "Família, para mim, é união, coisa que eu não tenho". Esse fato pode impulsionar a busca por ajuda fora do grupo familiar. Esse também foi um dos únicos grupos cuja estratégia de busca religiosa é preponderante ao enfrentamento focalizado no problema.

As exceções quanto ao uso majoritário da estratégia de enfrentamento com foco no problema são o GF1, cujo diagnóstico foi descoberto recentemente, e o GF4, em que o familiar (sexo F, 32 anos) pouco sabia sobre a doença, como no trecho: "Ainda não entendo a doença, não sabia que era grave". Em ambos os grupos, a estratégia de busca por práticas religiosas é preponderante (médias $=4,2$ ).

Também foram apontados como aspectos facilitadores do cuidado com o falcêmico: o tratamento/remédios (3 ocorrências); informação/ instruções médicas (3 ocorrências), ou seja, os próprios familiares reconhecem e estão abertos à colaboração dos profissionais da saúde na promoção de estratégias mais eficazes, tal como afirmam Seidl et al.(2001). 


\section{Considerações finais}

As análises permitiram caracterizar a rede de apoio e apontar as principais estratégias de enfrentamento adotadas pelos familiares de pessoas com doença falciforme. Investigados, esses aspectos possibilitam o planejamento e o desenvolvimento de intervenções psicossociais, envolvendo aspectos sociais, comportamentais e cognitivos, com vistas a melhorar a qualidade de vida do portador da doença e de seus familiares.

Considera-se que outras investigaçôes com uso de diferentes instrumentais de modo mais indagativo, como sugere Sluzki (1997), em relação aos utilizados neste estudo possibilitem maior compreensão da rede de apoio. Em relação às estratégias de enfrentamento, também se pode se pensar em estudos que abordem novas perspectivas teóricas como a proposta de compreensão do coping como ação regulatória, o qual, segundo Sameroff (2009), consiste na capacidade de regular o próprio comportamento por causa das demandas externas com base no conhecimento de si mesmo e do contexto.

As estratégias de coping são ações deliberadas que podem ser aprendidas, usadas e descartadas. Daí a importância de conhecer, estudar e proporcionar ambientes de tratamento e cuidado que facilitem e promovam estratégias de enfrentamento mais adequadas e redes protetivas para pessoas que se encontram em condição de doença crônica.

\section{Referências}

Albuquerque, F. J. B. de; Martins, C. R. \& Neves, M. T. de S. (2008, outubro, dezembro). Bem-estar subjetivo emocional e coping em adultos de baixa renda de ambientes urbano e rural. Estudos de psicologia, Campinas, 25(4),509-516.

Antoniazzi, A. S., Dell'aglio, D. D., Bandeira, D. R. (1998, julho, dezembro). O conceito de coping: uma revisão teórica. Estudos de Psicologia, Natal, 3(2), 273-294.

Brasil. Ministério da Saúde (2012). Doença falciforme condutas básicas para tratamento. Brasília: Ministério da Saúde. Recuperado a partir de http:// bvsms.saude.gov.br/bvs/publicacoes/doenca_falciforme_condutas_basicas. pdf. Acesso em 18/03/2013.

Brasil. Ministério da Saúde (2013). Doença falciforme: condutas básicas para tratamento. Brasília: Ministério da Saúde. Secretaria de Atenção à Saúde. Departamento de Atenção Especializada. 
Brasil. Ministério da Saúde. (2007). Manual da anemia falciforme para a população. Brasília: Ministério da Saúde. Secretaria de Atenção à Saúde. Departamento de Atenção Especializada.

Brito, R. C. \& Koller, S. H. (1999). Redes de apoio social e afetivo e desenvolvimento. In A. M. Carvalho (Org.). O mundo social da criança: natureza e cultura em ação. (pp. 115-130). São Paulo: Casa do Psicólogo.

Bronfenbrenner, U. (1996). A ecologia do desenvolvimento humano: experimentos naturais e planejados. Porto Alegre: Artes Médicas. (Trabalho original publicado em 1979).

Cordeiro, R. C. (2009, abril). Discriminação racial e de gênero em discursos de mulheres negras com anemia falciforme. Revista de Enfermagem, 13(2),352358.

Coyne, J. C. \& DeLongis, A. (1986, agosto). Going beyond social support: the role of social relationships in adaptation. Journal of Consulting and Clinical Psychology, 54(4), 454-460.

Folkman, S., Lazarus R. S., Dunkel-Schetter C., DeLongis A. \& Gruen, R. J. (1986). Dynamics of stressful encounter: cognitive appraisal, coping, and encounter outcomes. Journal of Personality and Social Psychology, 50(5), 992-1003.

Garmezy, N. \& Masten, A. S. (1991). The protective role of competence indicators in children at risk. In E. M. Cummings, A. L. Greene \& K. H. Karraker (Eds.), Life-span developmental psychology: perspectives on stress and coping. (pp. 151-174). Hillsdale, NJ: Erlbaum.

Lazarus, R. S. \& Folkman, S. (1984). Stress, appraisal and coping. New York: Springer Publishing Company.

Loureiro, M. M. \& Rozenfeld, S. (2005). Epidemiologia de internações por doença falciforme no Brasil. Revista de Saúde Pública,39(6),943-949.

Mensorio, M. S., Kohlsdorf, M. \& Costa Junior, A. L. (2009, abril). Cuidadores de crianças e adolescentes com leucemia: análise de estratégias de enfrentamento. Psicologia em Revista, 15(1),158-176.

Morais, N.A. \& Koller, S.H. (2004). Abordagem ecológica do desenvolvimento humano, Psicologia Positiva e Resiliência: ênfase na saúde. In S. H. Koller (Org.). Ecologia do desenvolvimento humano: pesquisa e intervenção no Brasil. 
(pp. 91-108). São Paulo: Casa do Psicólogo.

Narvaz, M. G. \& Koller, S. H. (2004). O modelo bioecológico de desenvolvimento humano. In S. H. Koller (Org.). Ecologia do desenvolvimento humano: pesquisa e intervenção no Brasil. (pp. 51-66). São Paulo: Casa do Psicólogo.

Nogueira, E. J. (2001). Rede de relaçôes sociais: um estudo transversal com homens e mulheres pertencentes a três grupos etários. (Tese de doutorado). Universidade Estadual de Campinas, Programa de Pós-Graduação em Educação, Campinas.

O’Brien, T. B. \& DeLongis, A. (1996, dezembro). The interactional context of problem-, emotion-, and relationship-focused coping: the role of the big five personality factors. Journal of Personality, 64(4),775-813.

Portaria n. 1.391/GM (2005, agosto). Institui no âmbito do Sistema Único de Saúde, as diretrizes para a Política Nacional de Atenção Integral às Pessoas com Doença Falciforme e outras Hemoglobinopatias. Brasília: Ministério da Saúde. Recuperado a partir de http://www.saude.mg.gov.br/images/documentos/por_1391.pdf.

Rutter, M. (1987). Psychosocial resilience and protective mechanisms. American Journal of Orthopsychiatry, 57(3), 316-331.

Sameroff, A. J. (2009). The transactional model the development: how children and contexts shape each other. Washington: American Psychological Association.

Seidl, E. M. F., Troccoli, B. T. \& Zannon, C. M. L. (2001). Análise fatorial de uma medida de estratégias de enfrentamento. Psicologia: Teoria e Pesquisa, 17(3), 225234.

Silva, L. F., Guedes, M.V.C., Moreira, R. P.\& Souza, A. C. C. (2002, janeiro,março). Doença crônica: o enfrentamento pela família. Acta Paulista de Enfermagem, 15(1),40-47.

Silva, R. B. Paiva e, Ramalho, A. S., Cassorla, R. M. S. (1993). A anemia falciforme como problema de saúde pública no Brasil. Revista de Saúde Pública, 27(1), 54-58.

Silveira, C. L. (2011). Rede de apoio social dos cuidadores de familiares com doença crônica de uma comunidade remanescente de quilombos. (Dissertação de Mestrado). Universidade Federal de Santa Catarina, Programa de Pós-Graduação em Enfermagem, Florianópolis.

Siqueira; A. C. Betts, M. K., Dell'aglio, D. D. (2006). Redes de apoio social e 
afetivo de adolescentes institucionalizados. Interamerican Journal of Psychology, 40(2), 149-158.

Sluzki, C. E. (1997). A rede social na prática sistêmica. São Paulo: Casa do Psicólogo.

Teixeira, M. B. \& Leão, S. de S. (2002). Empoderamento como estratégia de promoção da saúde no campo do envelhecimento. (Dissertação de Mestrado). Fundação Oswaldo Cruz, Escola Nacional de Saúde Pública. Recuperado a partir http:// portalteses.icict.fiocruz.br/transf.php?script=thes_cover\&id=000034\&lng=pt\&n $\mathrm{rm}=\mathrm{isso}$.

Vieira, V. A. (2002, janeiro, abril). As tipologias, variações e características da pesquisa de marketing. Curitiba, Revista da FAE, 5(1),61-70.

Zago, M. A. (2001). Defeitos hereditários das hemoglobinas. In M. A. Zago, R. P. Falcão, R. Pasquini (Eds.). Hematologia: fundamentos e prática. (pp. 279-287). Rio de Janeiro: Ateneu. 